\title{
A Preliminary Study of Literature Review on Health and Media Literacy in the Year 2015 Until 2020
}

\author{
Norhuda Salleh* ${ }^{1}$, Noor Syakirah Zakaria ${ }^{1}$ and Asmiaty Amat ${ }^{2}$ \\ ${ }^{1 \& 2}$ Faculty of Social Sciences and Humanities; \\ ${ }^{2}$ The Centre for the Promotion of Knowledge and Language Learning \\ Universiti Malaysia Sabah \\ Corresponding author: norhudasalleh@ums.edu.my
}

\begin{abstract}
Media literacy is the ability of individuals to understand, investigate, create, communicate, and think critically hence, media literacy should take part in accommodating health information in the evolving world. The globalization has captured the importance of media that not only educate and deliver information at the end of our fingertips but also as a powerful medium to influence. The objective of this article is to review the previous studies regarded of the level of media literacy and health the influences women particularly when making decisions on their postpartum practices after childbirth during the postpartum period. This articles also attempts to review whether food choices that are made to consider health factors or to rely heavily on local community traditions. This paper is a preliminary study of six years research related to the topic chosen. The literature research was restricted to studies published in English and Malay from 2015 to 2020.In order to understand about the media literacy and health of women, the past six years of research have conveyed that women do rely on internet, magazine, and radio for nutrition, dietary knowledge, and postpartum practices while simultaneously practicing old beliefs carried by the elderly of the family. Notably, social media and the general media play a significant role in providing information for mothers or women in general in regards to health communication retrieval and women are in no doubt have high media and health literacy when it comes to antenatal and postnatal. The relationship between media literacy influencing health and postpartum practices were consistent as majority of studies agrees that mass media influence mothers' pre and postpartum period regardless demography, income and educational level.
\end{abstract}

Keywords: Childbirth, Food, Health, Media Literacy, Women

\section{Introduction}

Media literacy is the ability of individuals to understand, investigate, create, communicate and think critically. Media literacy is essential to ensure that an individual is able to access, organize, analyze, evaluate and create messages in various forms. Media literacy is an important aspect to be given attention and focus, not only by researchers but also by other stakeholders to create a media-literate society. The importance of any country especially Malaysia to having a media literate society in the era of globalization is particularly important in relation to health. It is in line with the government's aspiration to becoming a developed nation at the same time as the health of its people is the best as outlined in the fifth core of one of the seven pillars of the Shared Prosperity Vision 2030 (WKB2030), which is social well-being. As a catalyst 
towards this, women in this context are one of the catalysts in realizing WKB2030. In this regard, this group needs to be given attention in bringing forth, knowledgeable and capable generations to contribute to the nation. Media literacy, especially in health, is one of the most important elements that need to be taken seriously. More specifically, media literacy is very much needed in the context of health involving women after childbirth because these groups are at high risk for various health complications.

\section{Literature Review}

The role and importance of media literacy have long been discussed since it was first made based in Malaysia in the 1980s when Malaysian Institution of Microelectronics Systems (MIMOS) became its sole provider in Malaysia (Asia Internet, 2010). Media literacy is the ability to literate, adhere, and utilize media. Consequently, new media began to the advent and find its way to compliment internet functions. Hence, the new media and the internet became the most reliable tool used or education purposes, and interaction. To operate and utilize any kind of media, media literacy is needed for everyone to comprehend the basics fundamental of media.

Simultaneously, since search engines became familiar to us along with the internet, many social media platforms were introduced as the result of the excavation of new media concerning every aspect namely education, economy, politics, entertainment, and even health. Social media is a computer-based technology that facilitates the sharing of ideas, thoughts, and information through the building of virtual networks and communities (Dollarhide, 2019). Within the context of this study, social media is said to play a significant role by being the mediator or channel of delivery of information for individuals pertaining to health information related to postpartum practices. Social media provide health care professionals with tools to share information, to debate health care policy, and practice issues, to promote health behaviors, to engage with the public to educate, and interact with patients, caregivers, students, and colleagues (Zulkefli, Iahad, \& Yusof, 2018).

Today, everyone was able to seek information at the tip of their fingers, as healthrelated questions can sometimes be humiliating to inquire when face-to-face with a health provider, doctor, or nurse, hence with the internet's help, most can address their concerns to the web without having to bear this embarrassment. Information seeking refers to the "purposive seeking for information as a consequence of a need to satisfy some goal" (Wilson \& Williams, 2000; Ahadzadeh \& Sharif, 2017). Meanwhile, Rahim, Ibrahim, Salim, and Ariffin (2019) defined health information as information related to health, including health service provided for individuals or communities. In particular, information and knowledge that involve postnatal or postpartum nutrition, dietary, physical activities, and so on may be limited for an individual, and having that said, the internet is left to be the only aid.

Health information seeking is a manifestation of self-health management. Importance of health information-seeking behavior is said that it can promote individuals' health knowledge, formulate their judgments, beliefs, and attitudes toward healthy behaviors accordingly and empower them to make an informed decision about health eventually (Goonawardene, Jiang, Tan, Park, \& Su, 2013; Jamal, Khan, AlHumud, Al-Duhyyim, Alrashed, Shabr, Alteraif, Almuziri, Househ, \& Qureshi, 2015; Ahadzadeh \& Sharif, 2017). Since this study revolves around the information-seeking 
or reliability of postpartum nutrition, dietary and practices of mothers during the confinement period in Kota Kinabalu Sabah.

When referring to health beliefs, attitudes, and behaviors, terms such 'taboo' have always managed to surface. Taboo in this study refers to the cluster of food that is restricted upon taken during the postpartum period that often lasts for three to eight weeks or up to 40 to 100 days according to common Malay practices. Another similar term that may be associated with taboo in this context is restriction, it is the prevention or restraining a person from committing anything that is considered 'wrong', unethical or unhealthy during the postpartum period. Some restrictions during postpartum include doing house chores, going out of the house, eating 'cold' food, and having intercourse or any extreme physical activities. Beliefs on the other hand is a set of acceptance, understanding, or faith that is usually upheld by individuals and it may differ to others.

The objectives of this paper is to review the previous studies regarded of the level of media literacy and health the influences women particularly when making decisions on their postpartum practices after childbirth during the postpartum period. This articles also attempts to review whether food choices that are made to consider health factors or to rely heavily on local community traditions. The selected articles from local and abroad were chosen to analyze the trend of postpartum practices patterns, beliefs of Malay, Chinese, Indian, and Indigenous women in Malaysia, postpartum taboos, roles of midwives, restrictions, dietaries, postnatal morbidity factors, health information pattern and their sources, postnatal depression indicators, postpartum support, postpartum nutritional knowledge, and health information seeking pattern in Malaysia.

This article review includes the studies of postpartum information and mass media utilization from other countries, valuable information of postpartum, health literacy information based on races, postpartum literacy limitation factors, effects on social media on mothers, mass media for postpartum social support, and mass media roles in helping women's health literacy and education.

\section{Methodology}

This is a narrative review of published quantitative and qualitative studies, review papers, and theses on past postpartum research practices, nutrition knowledge, and dietary and past research on media utilization or information sources for postpartum or health literacy. An electronic literature search was conducted using Mendeley. The literature research was restricted to studies published in English and Malay from 2015 to 2020. The keywords or phrases used during the literature search were childbirth, food, health, media literacy, and women. Once related articles were identified, their reference lists were also used to identify additional articles. There are 57 articles in total, 38 of them are Malaysian articles while the remaining are studies or articles published outside of Malaysia. Out of 57 articles, 41 articles have met the specific criteria for this study.

\section{Quality Assessment}

This paper is based on original articles, theses, review, and studies while conference paper, symposium papers are all excluded from this review. Paper duplications were also checked thoroughly to ensure no publication of articles in this review. Both abstract and conclusion were screened in detail to identify the scope of study. Lastly, references, bibliography, and citations were cross-checked to explore any similar studies. 


\section{Eligibility and Inclusion Criteria}

The list of relevant literatures was taken for comprehensive and thorough selection to match the criteria set for this research. The articles selected are published in either Malay or English. Among the themes that were included are postpartum practices patterns, support and nutritional knowledge, health information pattern health literacy, mass media utilization on postpartum nutrition, postnatal depression indicators, and effects of social media on mothers. During the literature collection, article with open access and non-open access were both selected. Quantitative study is widely used for most of the literature.

\section{Studies Included in Qualitative Synthesis}

Once the selection of 57 papers was completed, all the literatures' information was narrowed in Microsoft Excel to a descriptive table of analysis of the published literature synopsis, citation, objective, dependent and independent variable, instrument, sample, sample size, timeframe, analysis tool, relevant findings, and outcomes. This step was done to identify and analyze the main research or article streams and fulfill the gaps in the current study. This step also foresees the upcoming opportunities and challenges for the study.

\section{Findings}

The literature review of six years from 2015 until 2020 is divided into two themes; years of research, past postpartum research practices and health literacy which included nutrition knowledge, dietary and past research on media utilization or information sources for postpartum. To provide in-depth information on how evolved the postpartum practices in Malaysia, a straight-forward comparison will be made. There are 41 articles from 2015 to 2020 that divided into two themes of health literacy and postpartum practices in order to find out the level of media literacy and health the influences women particularly when making decisions on their postpartum practices after childbirth during the postpartum period. 
Table 1 Literature Review on Health and Media Literacy in the Year 2015 until 2020 by Health Literacy Theme

\begin{tabular}{|c|c|c|c|}
\hline \multicolumn{4}{|c|}{ THEME: HEALTH LITERACY } \\
\hline Title of the article & Author & Findings & $\begin{array}{c}\text { Year of } \\
\text { Publication }\end{array}$ \\
\hline $\begin{array}{l}\text { Impact of mass media on } \\
\text { the utilization of antenatal } \\
\text { care services among women } \\
\text { of rural community in } \\
\text { Nepal. }\end{array}$ & $\begin{array}{l}\text { Acharya, Khanal, Singh, } \\
\text { Adhikari, \& Gautam. }\end{array}$ & $\begin{array}{l}\text { A majority of mothers were exposed to mass media. Radio was accessible to most }(60.0 \%) \\
\text { of the partici- pants followed by television }(43.41 \%) \text {. Mothers exposed to mass media were } \\
\text { more likely to attending antenatal visits [Odds ratio (OR) 6.28; 95\% CI }(1.01-38.99)] \text {, } \\
\text { taking rest and sleep during pregnancy [OR } 2.65 ; 95 \% \text { CI }(1.13-6.26)] \text {, and receiving TT } \\
\text { immunization [OR 5.12; } 95 \% \text { CI }(1.23-21.24)] \text { than their non-exposed counterparts. }\end{array}$ & 2015 \\
\hline 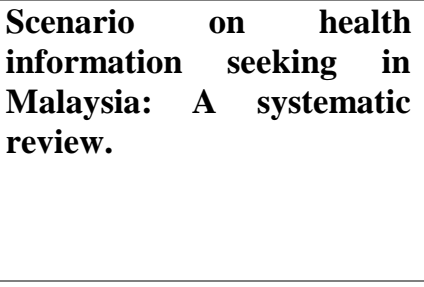 & $\begin{array}{l}\text { Hamzah, Mohamad, } \\
\text { Abdullah, \& Hadi Ayub. }\end{array}$ & $\begin{array}{l}\text { The study of the health information seeking in Malaysia is still minimal. From empirical } \\
\text { analysis perspective, there has not been much study on various issues arising in the context } \\
\text { of health information seeking. Scholars mentioned that although there are no significant } \\
\text { differences pertaining to information seeking in a different context in health, it however } \\
\text { must be noted that the issues inherent in the health context is different. This is due to the } \\
\text { various subject of analysis such as type of disease, the environment, and psychology, culture } \\
\text { and health status. }\end{array}$ & 2015 \\
\hline $\begin{array}{l}\text { Prevalence and risk factors } \\
\text { for postnatal depression in } \\
\text { Sabah, Malaysia: A cohort } \\
\text { study. }\end{array}$ & $\begin{array}{l}\text { Aza Sherin Mohamad } \\
\text { Yusuff, Tang, Binns, \& } \\
\text { Lee. }\end{array}$ & $\begin{array}{l}\text { A substantial proportion (14\%) of mothers had experienced depression during the first six } \\
\text { months postpartum in Sabah, Malaysia, based on our prospective cohort study. Antenatal } \\
\text { depression, lack of assistance with infant care from the husband, dissatisfaction with marital } \\
\text { relationship, and consistent worries about the infant, were all associated with an increased } \\
\text { risk of postnatal depression, according to the logistic regression analysis. Screening and } \\
\text { intervention programmes targeting these vulnera- ble subgroups of women during antenatal } \\
\text { and early postpartum periods are recommended to deal with the problem. }\end{array}$ & 2015 \\
\hline $\begin{array}{l}\text { Postpartum Health } \\
\text { Information Seeking Using } \\
\text { Mobile } \\
\text { Experiences of } \quad \text { Powes: } \\
\text { Income Mothers. }\end{array}$ & $\begin{array}{l}\text { Guerra-Reyes, Christie, } \\
\text { Prabhakar, Harris \& Siek. }\end{array}$ & $\begin{array}{l}\text { Interviewees reported almost exclusive use of mobile phones to access the Internet. Mobile } \\
\text { applications were widely used during pregnancy, but were not valuable postpartum. Face- } \\
\text { to-face information from medical professionals was found to be repetitive. Online } \\
\text { information seeking was mediated by default mobile phone search engines, and occurred } \\
\text { over short, fragmented time periods. College graduates reported searching for authoritative } \\
\text { knowledge sources; non-graduates preferred forums }\end{array}$ & 2016 \\
\hline $\begin{array}{l}\text { Nutritional knowledge, } \\
\text { attitude and practice } \\
\text { among antenatal and } \\
\text { postnatal mothers in }\end{array}$ & $\begin{array}{l}\text { Ikhsan, } \quad \text { Nasaruddin, } \\
\text { Othman, Aziz \& Ismail. }\end{array}$ & $\begin{array}{l}\text { Maternal education is the single most important predictor that may influence nutritional } \\
\text { knowledge and practice. However, there was no significant relationship between } \\
\text { education and nutritional attitude, as attitude may be inborn with them considering } \\
\text { one's different upbringing. It is crucial for a mother to be educated, as this will confer }\end{array}$ & 2016 \\
\hline
\end{tabular}


Hospital Tengku Ampuan Afzan (HTAA) good knowledge, attitude, and practice during the upbringing of their children to prevent vicious circle of poor nutritional attitude. tudy results emphasize the importance of empowering girls and women with proper adequate educations and to strengthen the nutritional and health education of our educational system. This study more education regarding nutrition in pregnancy need to be enhanced, as this will also help pregnant women to choose a healthy diet for safe pregnancy. Thus, this study will in turn help government in initiating intervention as early as before embarking the pregnancy period, targeting the appropriate group, especially the poorly educated women

The use and value of digital Lupton
media for information
about pregnancy and early
motherhood: A focus group
study.

The results revealed a high use of pregnancy apps: almost three-quarters of respondents had used at least one pregnancy app while half reported using at least one parenting app. The vast majority of respondents who had ever used a pregnancy app said that they found the apps useful or helpful, particularly for providing information, monitoring foetal development and changes in their own bodies and providing reassurance. While fewer women used parenting apps, those who did also found them useful as sources of information, for helping to monitor their children's growth and development and to provide reassurance. All respondents were asked what online media other than apps they used for pregnancy or parenting information or support. Only $9 \%$ of respondents said that they used no other online media. The answers from the other respondents demonstrated that websites remain very popular (57\% used them for pregnancy, $66 \%$ for parenting), followed by online discussion groups ( $26 \%$ for pregnancy, $28 \%$ for parenting) and Facebook (pregnancy 22 $\%$, parenting $33 \%$ ).

$\begin{array}{lr}\text { Online health information } & \text { Ahadzadeh \& Sharif } \\ \text { seeking among Malaysian } & \\ \text { women: } & \text { Technology } \\ \text { acceptance } & \text { model }\end{array}$

Findings also suggest that attitude was significantly predicted by perceived usefulness and perceived ease of use. Moreover, this study found that attitude partially mediates the influence of perceived usefulness on online health information seeking. Furthermore, perceived ease of use indirectly influences online health information seeking through attitude

perspective.

Inadequate health literacy

on childhood immunization and its predictors among antenatal mothers.
Nazatul

Yusrina

Out of 362 respondents, $81.2 \%$ were inadequate health literacy. The predictors were Mohamad Yusof, Nor maternal education, residential area (and utilization of government hospital. Accessibility Afiah Mohd Zulkefli, of health education with regard to immunization need to be strengthen among primigravida, Suriani Ismail, \& low education and those staying in rural area. In addition, health education also needs to Mohammad Faiz Abd emphasize on the individual that is employed and low economic status with underutilization 
of government hospital. A simplified education material with interesting pictures and using visual aids help illiterate people for better understanding.

$\begin{array}{ll}\text { Reproductive health Zimmerman } & \text { Some of these interventions have met information needs related to family planning, } \\ \text { information needs and } & \text { HIV/AIDS, sexually transmitted infections, violence against women, sexuality, pregnancy } \\ \text { maternal literacy in the } & \text { education, and emergency obstetric care }\end{array}$

of the literature.

\begin{tabular}{|c|c|c|c|}
\hline $\begin{array}{l}\text { The relationship between } \\
\text { media literacy and health } \\
\text { literacy among pregnant } \\
\text { women in health centers of } \\
\text { Isfahan. }\end{array}$ & $\begin{array}{l}\text { Akbarinejad, Soleymani, } \\
\text { \& Shahrzadi. }\end{array}$ & $\begin{array}{l}\text { The results showed that more than half of pregnant women covered by health centers have } \\
\text { inadequate or marginal health literacy. his discrepancy may be due to the fact that women } \\
\text { with high education and high social classes usually prefer to go to private clinics instead of } \\
\text { public health centers. Furthermore, a large percentage of respondents over age } 30 \text { were } \\
\text { housewives, which low levels of health literacy appears to be due to low educational levels. }\end{array}$ & 2017 \\
\hline $\begin{array}{l}\text { The Feasibility of } \\
\text { Providing Nutrition } \\
\text { Education Through a Wic } \\
\text { App To Augment Healthy } \\
\text { Eating, Breastfeeding, and } \\
\text { Physical Activity Behaviors } \\
\text { Amoung Wic Participants. }\end{array}$ & Monica Silva & $\begin{array}{l}\text { This study strongly support the strategy of a WIC app to be an effective tool for } \\
\text { supplementing nutrition education. Smartphones may be able to bridge various } \\
\text { socioeconomic gaps to facilitate targeted health behaviors. Observations made in the context } \\
\text { of this research also establish the perceived ability for WIC app features to address cited } \\
\text { barriers such as lack of information, support, and strategies for altering health related } \\
\text { behaviors, it also suggest similar usage of technology can improve health behavior } \\
\text { maintenance by increasing confidence level and enhancing patient to provider } \\
\text { communication within this population. }\end{array}$ & 2017 \\
\hline $\begin{array}{l}\text { Benefits of Social Media } \\
\text { Platform in Healthcare }\end{array}$ & $\begin{array}{l}\text { Nur Ain Zulkefli, } \\
\text { Noorminshah A. Iahad, \& } \\
\text { Ahmad Fadhil Yusof. }\end{array}$ & $\begin{array}{l}\text { Several studies have shown that social media platforms facilitate patients to share and } \\
\text { acquire health information and knowledge such as symptoms, with health experts such as } \\
\text { medical doctors or medical researchers. A review study showed that Facebook and Twitter } \\
\text { are used by both researchers and patients with the aim of accessing information related to } \\
\text { epilepsy while Facebook was utilized by the patients, survivors, and donors in order to share } \\
\text { and exchange cancer information. While conducting a review study, found that health } \\
\text { information shared on social media platforms is usually targeted at a range of populations; } \\
\text { from the general public to specific patients sing social media platforms for healthcare in } \\
\text { general public are believed to facilitate them to increase awareness related to health and }\end{array}$ & 2018 \\
\hline
\end{tabular}


disease. Also, it is targeted to educate the general public to understand and reduce the public stigma regarding particular disease in order to motivate and encourage patients to keep strong to fight with their disease. Whereas, for patient perspective, integrating social media platforms for healthcare purposes give an opportunity for them to acquire, share and exchange information and social support

Mother, baby and Archer \& Kao.
Facebook makes three:
does social media provide
social support for new
mothers?

The focus groups revealed that Facebook is used by the majority of mothers as their main (or only) social media platform, which aligns with the general population's usage of social media. A very small minority did not use Facebook, and this was the result of a conscious decision to stay away from social media. A smaller number of women discussed using Twitter, Pinterest or Instagram (Instagram was used to 'follow' older children). While Instagram usage may have increased since the focus groups were conducted in late 2015, this finding broadly reflects the mainstream adult population's usage, with $94 \%$ of social media users in Australia on Facebook in 2017, followed by 46\% on Instagram (Sensis, 2017). The messaging app WhatsApp was popular with women whose families were overseas or interstate. Email was still used by the women (and some playgroups) for some forms of communication; however, it was seen as more formal and participants were overwhelmed by the volume of emails from commercial interests.

Social media as social Baker \& Yang support in pregnancy and the postpartum.

The ubiquity of the online environment along with changing family structures and increasing numbers of single mothers, working mothers, and mothers who do not live near extended family contribute to the creation of new models of social support which incorporate social media networks. the potential exists for social media networks to provide the interest, caring concern, and attention that make a pregnant woman and a new mother feel respected and valued, and provide the emotional support to promote her individual strengths and capabilities. However, As a preliminary survey of social media use among perinatal women, this study provides a big picture of the phenomenon and was not designed to characterize detailed demographics or granularities about social media use.

Associations between social Ginja, Coad, Bailey, Social support is associated with mental well-being and self-efficacy in antenatal first-time support, mental wellbeing, Kendall, Goodenough , mothers. This association was not significantly affected by general technology use as $\begin{array}{llll}\text { support, mental wellbeing, Kendall, Goodenough, mothers. This association was not significantly affected by general technology use as } \\ \text { self-efficacy and technology } & \text { Nightingale, Smiddy, measured in our survey. Future work should investigate whether pregnancy-specific }\end{array}$ use in first-time antenatal Day, Deave, \& Lingam. technologies yield greater potential to enhance the perceived social support, wellbeing and women: Data from the self-efficacy of antenatal women

women: Data from
BaBBLeS cohort study. 
Traditional Belief and Ghani \& Salehudin. Practice on Postpartum Recovery among Mothers in East Coast of Peninsular Malaysia.

Perception on Postpartum Basir, Rahman, Abu Dietary Practices Among Bakar, \& Shukri. Malay Women in Kuantan, Pahang.
The factors that influenced respondents to do postpartum care practice were self- belief, family tradition, family pressure, influenced by close friends, and convenience. It has been found that the family tradition was the most influenced factor among respondents with 83 $\%$ of the mothers. There were five elements that contribute to knowledge of postpartum care which were family tradition, acquired health education, recommended by midwife, internet and others. Family tradition has contributed the most to knowledge of postpartum care among mothers

It was found that $100 \%$ of respondents mentioned that they do observe the traditional postpartum practices after childbirth with most of them $(63.0 \%)$ chose to confine for up to 44 days. Flavored rice, roti canai and various types of noodle were generally avoided during postpartum period due to their oily/fatty property. Tubers, and most fruits and vegetables were also avoided due to their old property. Moreover, the famous reason for exclusion of fish causing itchiness for seafood. Milk and dairy products were included in majority of respondents diet. Out of $80,43(53.8 \%)$ respondents avoided soy sauce because it was believed to give negative effect on wound healing. Other than that, iced drink, tea and sugarcane drink were avoided due to their cold and 'sharp' properties. In addition, statistical tests of all food items show that there is no difference in terms of level of acceptance for each food between women delivered via normal delivery or caesarean section. It is concluded that postpartum food taboo beliefs are still prevalent among Malay women. Extensive food prohibition and restriction causes limited food choices which may affect mothers nutritional intake. Thus, a more balanced diet should be recommended for Malay mothers during postpartum period to ensure adequate nutrient intake, as much as culturally acceptable.

New media literacy and Shin, \& Hasmah
media use among
university Zanuddin.

The findings showed that most of the students are at the medium level of new media literacy. No significant difference was found in new media literacy based on demographic factors, except media use which also had a small positive correlation with two dimensions of new media literacy, namely functional prosumption and critical prosumption. The findings served as a valuable input for public or private institutions or organizations that are responsible or keen in tackling fake news.

Health information Rahim, Ibrahim, Salim, \&

engagement factors in Ariffin

Malaysia:

The growing trend of online health-seeking behaviors and demand for the availability of validated health information on social media platforms requires effective strategies by health organizations to disseminate health information to internet users. An educational or risk 


\section{analysis of facebook use by} the ministry of health in 2016 and 2017.

\section{Web elements for health promotion in Malaysia.}

Marwan Noman, Koo, Tee, \& Krishnan.

communication post appealing to emotions such as curiosity, fear, and anxiety can change public perception and encourage behavioral actions. Moreover, a FB post with video content and timely dissemination of messages can achieve better audience engagement on social media. These findings have important implications for the development of effective social media health communication strategies by health organizations in Malaysia. Although a causal conclusion cannot be inferred from this study, at a minimum, we can conclude that the health information factors we analyzed in this study will achieve better engagement rates on social media.

Based on the discussions obtained on the factors of web elements and motivation for health promotion, the results of this paper highlight the requirements of web- based health promotion users, especially on web ele- ments on users' motivation and future usage. It also highlights implications for web developers and policy- makers to overcome barriers and issues affecting motivation factors in enabling participants to use web- sites for health promotion. The difficulty with the model which thus highlights is the 'mechanism of change' category which appears vague. If the model is to be an input-output model of behaviour change, it must be adequate regarding the rela- tionship between the components that display. he categories related to motivation found in this study are avoid burdens, engagement, helpful, intention and encouragement. The notion 'avoid burdens' relates to features of a website. It is apparent that this example (avoid burdens) is very different from the notion of 'helpful', It is not the characteristic within the website it- self. Another research finding appear in this study is the definition of the term intention. It is unclear whether this refers to the intention of the research subject when they are engaged with the website or to the purpose of the website.

MHealth communication to Mbuthia, strengthen postnatal care Fichardt. in rural areas: A systematic review.
Reid, \& The results of 11 articles were synthesised to report the determinants of PNC uptake. Determinants were aligned to the Integrative Model of Behaviural Prediction (IMBP). Oneway mobile phone messaging was the most common type of mHealth communication used. mHealth communication influenced mothers' intentions, skills, and environmental constraints associated with uptake of PNC. Intentions were influenced by attitudes, perceived norms and self-efficacy. Positive attitudes, as well as changed attitudes toward PNC practices were observed. Perceived norms that were enhanced were delivery at a health facility with immediate PNC, seeking of reinforcement and professional health support of newborn care practices, and male partner support. Improved self-efficacy was demonstrated
2019 
by mothers who attended scheduled appointments and they were confident with regard to newborn care practices. Skills for PNC that were improved included cord care, thermal care, appropriate breastfeeding and problem-solving. The environmental constraints faced and which were addressed in the studies included inaccessibility, unavailability and unaffordability of PNC services in rural areas.

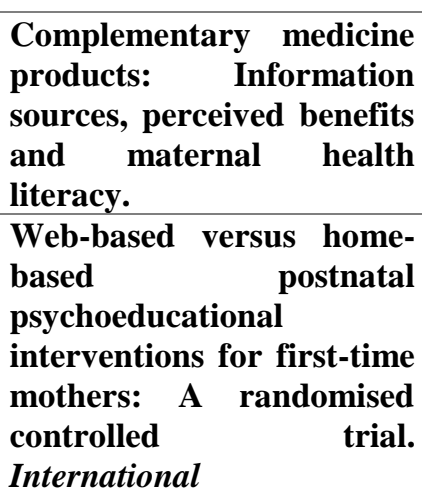

Use of Social Media in Huo,

Health Communication: Hong,Turner, Mainous,

Findings From the Health \& Bian

Information National

Trends Survey 2013, 2014,

and 2017.

Barnes, $\quad$ Barclay,
McCaffery, \& Aslani.
$\mathrm{He}$

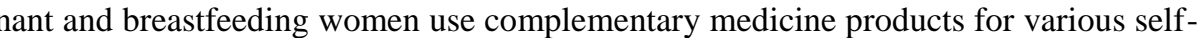
perceived benefits related to their own, unborn or breastfeeding babies' health. Examining these with reference to an interactive health literacy model helps identify the decisionmaking process mothers undergo when choosing to use complementary medicine products.

Jiao, Zhu, Chong, Chan, Luo, Wang, Hu, Chan, \&

The web-based intervention improved self-efficacy at post-test 1 (mean difference $=2.68$, $\mathrm{p}=0.028$ ) and reduced postnatal depression at post-test 3 (mean difference $=-1.82$, $p=0.044)$, while the home-based intervention did not show significant effect on these two outcomes at all post-tests. Both web-based and home-based interventions helped mothers to get better social support at all post-tests than those in the control group. Mothers in both web-based and home-based intervention groups were more satisfied with the postnatal care than those in the control group at all post-test time points The web-based intervention had better effects on improving self-efficacy, social support, and postnatal depression, which should be introduced to first-time mothers for better postnatal care.

Desai, Respondents in the year 2014 had a higher odds of social media use for exchanging medical information compared to those in the year 2013. Respondents who used social media for exchanging medical information had higher cancer knowledge and more reasonable and optimistic views about cancer. The use of social media to share health information in social media platform has reduced significantly over time, while the use of social media to exchange medical information with a health-care professional has increased. The findings in the opposite direction in temporal trend in the use of social media to share health information and trend to exchange medical information with a health-care professional suggest heterogeneity in health communication. The overall rate of respondents in use of social media to share the health information in $2017,16 \%$, has been more than doubled compared with the rate of $6 \%$ reported in a research 
A social media intervention to improve nutrition knowledge and behaviors of low income, pregnant adolescents and adult women.

Vander Wyst, Vercelli, Further efforts are needed to educate this high-risk community on prenatal nutrition and to O'Brien, Cooper, motivate dietary change for maternal and child health outcomes. This is especially important Pressman, \& Whisner. considering that the majority of participants who entered pregnancy as overweight or obese were more likely to experience EGWG during the intervention. Although teens have increased access to social media, the adults had higher levels of participation during this study. Future interventions are needed to further evaluate the type, frequency and sources of sugar consumed by this population and the best way to implement social media interventions in an effective and enjoyable way.however, overall knowledge of MyPlate Guidelines was limited. Social media-based education was well received by participants but did not result in large changes in dietary intake and knowledge.

\section{Pregnancy-related}

sharing in the social media

era among expectant

mothers in China:

Qualitative study. information seeking and

Zhu, Zeng, Zhang, Evans, $\& \mathrm{He}$.

Overall, 80\% (16/20) of participants were aged in their 20s (mean 28.5 years [SD 4.3]). All had used social media for pregnancy-related purposes. For the seeking behavior, 18 codes were merged into 4 themes, namely, gravida, fetus, delivery, and the postpartum period; whereas for sharing behaviors, 10 codes were merged into 4 themes, namely, gravida, fetus, delivery, and caretaker. Lurking, small group sharing, bad news avoidance, and crosschecking were identified as the preferred patterns for using social media. Overall, $95 \%$ $(19 / 20)$ of participants reported a positive mental impact from using social media during their pregnancy.

Information and Tang, Gerling, Chen, \& communication systems to Geurts tackle barriers to

breastfeeding: Systematic search and review. 
Health literacy level and Hakkak,

related factors among Rajabzadeh,

Joveini, The health literacy of $387(98.2 \%)$ was at optimal level. The linear regression results revealed a significant relationship between health literacy and age and educational level of pregnant women referring Robatsarpooshi, Tori, pregnant women. This study demonstrated that the health literacy was a great deal in most to bojnord health centers in Haresabadi, \& Hosseini of the women under study. However, the importance of health literacy in women and maternal health highlights that the health authorities in the country need to develop appropriate educational programs to promote the health literacy level and to empower this stratum.

A comparative study on Kim, Gray, Li, Park, Lee,
nutritional knowledge and \& Song
dietary behavior between
Korean and Chinese
postpartum women.
knowledge and habits. Also, more pregnancy-related nutrition education should be provided and various and effective nutrition education programs, which not only transfer information but can be practiced in the actual life, should be developed.

\begin{tabular}{|c|c|}
\hline $\begin{array}{l}\text { What matters to women in } \\
\text { the postnatal period: A } \\
\text { meta-synthesis } \\
\text { qualitative studies. }\end{array}$ & $\begin{array}{l}\text { Finlayson, Crossland, } \\
\text { Bonet, \& Downe }\end{array}$ \\
\hline $\begin{array}{l}\text { A systematic literature } \\
\text { review paper on online } \\
\text { medical } \\
\text { applications in Malaysia. }\end{array}$ & $\begin{array}{l}\text { Khan, } \\
\text { Mustapha, } \\
\text { Arshad, }\end{array}$ \\
\hline
\end{tabular}

Review of findings from 36 studies from 15 countries published between 2003 and 2019 demonstrates that a positive postnatal experience is one in which women are able to adapt to their new self-identity and develop a sense of confidence and competence as mothers, adjust to changes in their intimate and family relationships, including their relationship to their baby, navigate ordinary physical and emotional challenges, and experience the dynamic achievement of personal growth as they adjust to the 'new normal' of motherhood and parenting in their own cultural context. Effective, culturally appropriate family, community and professional support and activities can help women to overcome the exhaustion, and physical, emotional and psychological stress of the early postnatal period. mHealth apps are very common and the availability of internet with android smartphones are growing day by day. Traditional Health Care of Malaysia is top of the list in the world, but the mHealth still needs to improve in the region. Past studies in the mHealth are discussing physical health and wearable devices in details with connectivity to smartphones but serious diseases are cover in very some studies. Like diabetes and HIV apps and patient are not highlighted in the collected data. Patient record management and coordination with 
families are also part of some research studies and that is very important for recovery in some cases. The security concerns are related to mHealth apps and some people are not trusting apps due to too much information asked by applications during installation. Researchers need to point out the agenda in future studies to overcome the concerns of users about security issues. Normally mHealth applications are very much user-friendly and people with a basic education can use very comfortably the features of apps. Some applications are still very much complicated, especially with old people and uneducated

\section{Table 2 Literature Review on Health and Media Literacy in the Year 2015 until 2020 by Postpartum Theme} THEME: POSTPARTUM PRACTICES

\begin{tabular}{|c|c|c|c|}
\hline Title of the article & Author & Findings & $\begin{array}{c}\text { Year of } \\
\text { Publication }\end{array}$ \\
\hline $\begin{array}{l}\text { Traditional Postnatal Care } \\
\text { in Restoring Women's } \\
\text { Physical and Mental Health }\end{array}$ & Ministry of Health & $\begin{array}{l}\text { There was limited fair level of retrievable evidence that suggest the effectiveness of } \\
\text { traditional postnatal care in restoring women's physical (breast pain) and mental health } \\
\text { (postnatal depression, anxiety, stress levels and quality of sleep). However, there was no } \\
\text { retrievable evidence on safety and cost-effectiveness of traditional postnatal care. A } \\
\text { postnatal care package consisting of deep tissue massage, hot compression (tungku) and } \\
\text { abdominal wrapping (barut) as well as postnatal breast massage are provided free of charge } \\
\text { in the Traditional and Complementary Unit in several dedicated governmental hospitals. }\end{array}$ & 2015 \\
\hline $\begin{array}{l}\text { Traditional postpartum } \\
\text { practices among Malaysian } \\
\text { mothers: A review }\end{array}$ & $\begin{array}{l}\text { Fariza Fadzil, Khadijah } \\
\text { Shamsuddin, \& Sharifa } \\
\text { Ezat Wan Puteh. }\end{array}$ & $\begin{array}{l}\text { This review shows that Malaysian mothers have certain postpartum practices that they } \\
\text { considered to be important for preventing future ill health. Despite the perceived differences } \\
\text { in intra-ethnic postpartum practices, most Malaysian mothers, although from different } \\
\text { ethnicities, share similarities in their postpartum regimens and practices in terms of beliefs } \\
\text { and adherence to food taboos, use of traditional postpartum massage and traditional herbs, } \\
\text { and acknowledgment of the role of older female family members in postpartum care. }\end{array}$ & 2016 \\
\hline $\begin{array}{l}\text { Factors associated with } \\
\text { severe maternal morbidity } \\
\text { in Kelantan, Malaysia: A }\end{array}$ & $\begin{array}{l}\text { Noor, Hazlina, Aziz, \& } \\
\text { Sulaiman. }\end{array}$ & $\begin{array}{l}\text { Study suggests the enhanced screening and monitoring of women of advanced maternal age, } \\
\text { women with past pregnancy complications, those who underwent caesarean section } \\
\text { deliveries, those who delivered preterm and the mothers referred to tertiary centres as they }\end{array}$ & 2016 \\
\hline
\end{tabular}


comparative crosssectional study.

Postpartum dietary
restrictions and taboos Abdullah, Nilan, \& among indigenous Temiar Germov

among indigenous Temiar
women in Peninsular

Malaysia: A qualitative

study

\section{Postnatal Care Practices Zuraidah Mohd Yusoff, among the Malays, Chinese Asmiaty Amat, Darlina and Indians: A Naim, \& Saad Othman}

Comparison are at increased risk of severe maternal morbidity. Identifying these factors may contribute to specific and targeted strategies aimed at tackling the issues related to maternal morbidity.

Despite variations in locations, there were five agreed prohibited food items during the pstpartum period: cooking oil, salt, monosodium glutamate, sugar, and meat from game or from seven, eight, and fourteen days to one month. Besides food restrictions, there were other prescribed avoidances for mothers after delivering a baby. Conclusion: Prohibitions placed upon women during the postpartum period are intended to protect the new mother, the newborn baby and also the community. It appears that regardless of whether they live in the most traditional or the least traditional locations, the Temiar lineage and societal norms in the form of taboos during the female reproductive cycle are handed down to the new generation by their elders.

For the Chinese community, the confinement period observed by woman who had given birth depends on the individual but usually it spans a period of one month (30 days) or up to 44 days as the duration observed by the Malay woman. the Chinese are also very concerned with food and nutrition during the confinement period. During this period the woman is not encouraged to drink lot of plain water instead the decoction of dried longan and red dates are preferred. The Chinese society also emphasized on taking herbs such as ginseng soup, red date and 'lihing' during confinement.However, Chinese does not perform the barut, tangas or any steaming rituals like the malays. The postnatal practices among the Indians are rather similar to those practices among the Malays. After delivery the woman or new mother is allowed to bathe but only with warm water that has been boiled with herbs such as neem (Azadirachta indica), mengkudu (Morinda citrifolia) and lemuni Vitex Trifolia var Negundo) leaves.Similar to the Malay and the Chinese, the Indian also observed some food restriction during the confinement period.The basic factor in the postnatal care that was greatly emphasized by the three races is the fear of the 'wind' and cold which can caused illnesses such as body aches, fever and bloating in the woman which would hinder recovery. Food restriction is being observed in all the three races. The slight differences observed in the concept and practice between the three races is due to the different culture inherited from the elderly. 
Maternal Mortality in Achanna, Krishnaswamy, Major causes of maternal deaths were identified in the CEMD exercises; these were utilized

Malaysia : Progress Made Ponnampalam,

Towards Millennium Bondhu.

Development Goal (MDG )

5 - An Analysis of

Published Data.

Dietary Practices Among

Malay Women in Kuantan,

Pahang

The "irrational" taboos

and "irrelevant" traditions Mun, Faiz Sivaratnam, \& Diana related to postpartum Safraa Selimin women's health and well-

being Shukri
\& to devise key indicators and protocols and to address obstetric calamities. The provision of emergency obstetric services, early recognition and management or referral of complicated cases is pivotal. Additional public health activities, such as immunization campaigns, nutritional programmes, family planning services, alleviation of poverty, provision of education and empowerment, access to housing, have made significant impact on maternal health and reproductive services.

Siti Munirah Abdul Basir, It was found that $100 \%$ of respondents mentioned that they do observe the traditional Muhammad Safwan postpartum practices after childbirth with most of them $(63.0 \%)$ chose to confine for up to Abdul Rahman, Wan 44 days. Flavored rice, roti canai and various types of noodle were generally avoided during Azdie Mohd Abu Bakar, postpartum period due to their oily/fatty property. Tubers, and most fruits and vegetables \& Nor Azwani Mohd were also avoided due to their old property. Moreover, the famous reason for exclusion of fish causing itchiness for seafood. Milk and dairy products were included in majority of respondents diet. Out of $80,43(53.8 \%)$ respondents avoided soy sauce because it was believed to give negative effect on wound healing. Other than that, iced drink, tea and sugarcane drink were avoided due to their cold and 'sharp' properties. In addition, statistical tests of all food items show that there is no difference in terms of level of acceptance for each food between women delivered via normal delivery or caesarean section. It is concluded that postpartum food taboo beliefs are still prevalent among Malay women. Extensive food prohibition and restriction causes limited food choices which may affect mothers nutritional intake. Thus, a more balanced diet should be recommended for Malay mothers during postpartum period to ensure adequate nutrient intake, as much as culturally acceptable.

It was found that in Malaysia, certain postpartum traditions, including food taboos and behavioural and physical restrictions were conducted with the aim of maintaining the wellbeing of mother and baby, and to improve the healing process. Some of the practices were found to be irrelevant, whilst others had beneficial health impacts. Based on this review, the practice of certain taboos and traditions during the postpartum period was found to have both advantages and disadvantages. A rational approach is needed to weigh the practice against maternal safety and health. Thus, healthcare personnel should be sensitive to the role of taboos and traditions in the postpartum care of patients. The practice of traditions and 
taboos should be monitored for safe practice, along with a need for community- based education to avoid any unwanted issues as a result of its practice.

The Fading Birth Practice : Sh Fatimah AlZahra Syed This traditional cultural belief imposed certain childrearing and parenting ideals; extended $\begin{array}{llll}\text { Urban Malay } & \text { Mothers in } & \text { Hussien } & \text { familial support is present and expected, childrearing was shared with other familial } \\ \text { Malaysia } & \text { Negotiating } & & \text { members, mothering was learned and taught within this period in stages, and there was a }\end{array}$ Confinement Practice distinction between female and male realms within the family. Thefamilies that practised berpantangenjoyed more familial support in the first few weeks which was intertwined with their beliefs in confinement. Postpartum mothers are considered to be in a weak and vulnerable state, they are expected to be relieved of any household duties andmust eat a particular diet for recovery. Typically, first-time mothers will return to their maternal home or have their mothers stay with them. The confinement period was governed by clear female and male spheres andfocused on the maternal figures; the new mother, the grandmother, and the confinement lady or female masseuse.

\begin{tabular}{ll}
\hline Traditional Practices & Hla Myint, Rao, Mie Cho \\
during Postpartum Period & Win, \& Rajan. \\
among Women in Ampang, & \\
Malaysia.
\end{tabular}
Malaysia.

\begin{tabular}{lrlr}
\hline Attitude & Towards & Kumar & Mohanty, \\
Traditional, & & Fatimah binti \\
Complementary & and & Muhammad Nor, Noor \\
Alternative & Medicines & Faaezah binti Mohd \\
(T\&Cam) and Its Use & Sadek, Ohn Mar, \& \\
Among Women During & Author Basanta Kumar \\
Antenatal and Postnatal & Mohanty. \\
Period & &
\end{tabular}

Results showed 232 out of 235 women $(98.7 \%)$ practiced different traditional methods during postpartum period. Among variety of methods used, traditional massage (68.9\%) is the most common method practised by three races (Malay, Indian and Chinese). Showering with herbs $(67.2 \%)$ and cooking with herbs $(59.1 \%)$ were the second and third line popular traditional methods respectively. In addition, $(29.8 \%)$ of women used some practices to increase breast milk production. Most of the women used more than one traditional methods. In conclusion, although there are many advanced modern technologies in medical field and in well facilitated urban areas, most of the women are still using their own traditional practices according to their races and cultures.

103 respondents, $66.02 \%$ were antenatal and $33.98 \%$ were postnatal women with the mean age of 29.72 years. Prevalence of T\&CAM among the participants was $25.24 \%$. T\&CAM use was not prevalent among pregnant or breast feeding mothers $(\mathrm{p}<0.05)$. There was no significant association of use of T\&CAM with sociodemographic variables. The majority $(95.15 \%)$ of the respondents demonstrated good attitude towards T\&CAM use. Dietary method (restraining some food) was the most commonly practiced method. "The rest methods" were used by $30.10 \%$ of the respondents, followed by massage and hot stones Source: Author $(24.27 \%)$, herbal bath $(21.36 \%)$, herbal drinks $(9.71 \%)$ and abdominal wrap $(5.83 \%)$. 
(C) 2018, UCTS Publisher.

Submitted: 18 October 2020 Accepted: 19 December 2020 Published: 31 December 2020

\section{Discussion}

This review concludes literature on the relationship between the previous studies regarding the level of media literacy and health that influences women particularly when making decisions on their postpartum practices after childbirth during the postpartum period. In the overall studies there were multiple measures and unique definitions of health and media literacy. There are 41 articles from 2015 to 2020 that are divided into two themes of health literacy and postpartum practices in order to find out the level of media literacy and health the influences women particularly when making decisions on their postpartum practices after childbirth during the postpartum period. Results of suggesting media and health literacy in Malaysia were prominent as majority agrees that it is in a pristine understanding while only a few other studies that suggested otherwise. Additionally, literacy of both media and health are associated with education level and income.

The relationship between cultural, demographic and race were inconsistent across studies in terms of postpartum practices and there are few studies that compares the postpartum practices differences between race, ethnicity, interstate and West Malaysia and East Malaysia. However, the differences of postpartum practices do differ and evolve within the timeframe of 2015 to 2020 (e.g., dietary, nutrition, taboos, and restrictions) as health and media literacy has influenced the traditional beliefs of postpartum care. Despite the perceived differences in intra-ethnic postpartum practices, most Malaysian mothers share similarities in their postpartum regimens and practices in terms of beliefs and adherence to food taboos, use of traditional postpartum massage and traditional herbs, and acknowledgment of the role of older female family members in postpartum care (Fadzil, Shamsuddin, \& Puteh, 2016). In addition, the role of education level, demographic (rural vs suburban) and income has contributed to this change.

The relationship between media literacy influencing health and postpartum practices were consistent as majority of studies agrees that mass media influence mother's pre and postpartum period regardless demography, income and educational level. A majority of mothers were exposed to mass media, radio was accessible to most of the participants followed by television and mothers exposed to mass media were more likely to attending antenatal visits (Acharya, Khanal, Singh, Adhikari, \& Gautam, 2015). To add, the relationship between mothers using mass media information for postpartum practices are also consistent as they take into consideration of the information given even though majority mothers are also influenced by elders of community, traditions and their mothers before them. This traditional cultural belief imposed certain childrearing and parenting ideals; extended familial support is present and expected, childrearing was shared with other familial members, mothering was learned and taught within this period in stages, and there was a distinction between female and male realms within the family (Syed Hussein, 2019).

Additional public health activities, such as immunization campaigns, nutritional programmes, family planning services, alleviation of poverty, provision of education and empowerment, access to housing, have made significant impact on maternal health and reproductive services (Achanna, Krishnaswamy, Ponnampalam, \& Bondhu, 2018). The slight differences observed in the concept and practice between the three races is due to the different culture inherited from the elderly (Yusoff, Amat, Naim, \& Othman, 
(C) 2018, UCTS Publisher.

Submitted: 18 October 2020 Accepted: 19 December 2020 Published: 31 December 2020

2018). It appears that regardless of whether they live in the most traditional or the least traditional locations, the Temiar lineage and societal norms in the form of taboos during the female reproductive cycle are handed down to the new generation by their elders (Syed Abdullah, Nilan, \& Germov, 2016).

The decision of practicing postpartum care after childbirth during postpartum period between all races in Malaysia regardless income, demographic and education level was consistent. The minimal duration of postpartum was set to be 44 to 100 days. It was found that $100 \%$ of respondents mentioned that they do observe the traditional postpartum practices after childbirth with most of them (63.0\%) chose to confine for up to 44 days (Basir, 2018). The duration of postpartum care will differ amongst individuals however the decision of practicing postpartum care post-delivery is the same. The slight differences observed in the concept and practice between the three races is due to the different culture inherited from the elderly (Yusoff et al., 2018). Results showed 232 out of 235 women $(98.7 \%$ ) practiced different traditional methods during postpartum period. Among variety of methods used, traditional massage $(68.9 \%)$ is the most common method practised by three races (Malay, Indian and Chinese). Showering with herbs $(67.2 \%)$ and cooking with herbs $(59.1 \%)$ were the second and third line popular traditional methods respectively. In addition, $(29.8 \%)$ of women used some practices to increase breast milk production. Most of the women used more than one traditional methods. In conclusion, although there are many advanced modern technologies in medical field and in well facilitated urban areas, most of the women are still using their own traditional practices according to their races and cultures (Hla Myint, Rao, Mie, \& Rajan, 2019).

In overall studies, there are several models and theories that are interrelated with the current study and may be used to describe and support the findings. Among the theories and models that correlates with media literacy is the Domestication theory (Domestication-Communication Theory, n.d.) and Technology Acceptance Model (Charness \& Boot, 2016). While few other theory and model that may help is the Social Support theory (Kort-Butler, 2017) and Health Belief model (Health Behavior and Health Education, 2019). However, the conceptual model that fits the study is the Model of Health Literacy (Sorenson et al., 2015) and best suggested using the European health literacy survey (HLS-EU) questionnaire in data collection. This method will allow to identify the rate of health literacy that influences postpartum practices for mothers in postpartum period.

In the overall literature, most studies of media and health literacy involving postpartum practices was done separately. There are several studies that combines the literacy of media and health and connects the contribution of demographic into the study but there is no study that suggested the three combination of media and health literacy in influencing postpartum practices. Thus, to measure the development of mass media or media literacy in influencing mothers' postpartum practices in postpartum period needs critical understanding. Therefore, both health and media literacy must have to distinguish indicators that surpass a certain level of literate-ness of both health and media. 
(C) 2018, UCTS Publisher.

Submitted: 18 October 2020 Accepted: 19 December 2020 Published: 31 December 2020

\section{Conclusion}

To conclude, the past six years of research have conveyed that women do rely on internet, magazine, and radio for nutrition, dietary knowledge, and postpartum practices while simultaneously practicing old beliefs carried by the elderly of the family. Mothers, grandmothers, midwives, traditional birth attendants, and 'bidan' are relied on as emotional supporter for mothers while giving advice either traditional or modern towards mothers in confinement period. Notably, social media and the general media play a significant role in providing information for mothers or women in general in regard to health communication retrieval and women are in no doubt have high media and health literacy when it comes to antenatal and postnatal. Based on comparison researchers, women residing in rural areas tend to have low media and health literacy compared to women residing in urban areas, this applies to higher educated women and occupation. Government programmes such as campaigns and education programmes are proven to curb the health literacy rate. In terms of social media as social support and being a source of the health communication platform, it is undeniable true all forms of media provide a generous amount of support through giving real-life experience and sharing. However, further research must be done to identify the effectiveness of traditional practices for postpartum scientifically, and social media as a form of social support help as the mixed results may be unaccounted.

\section{References}

Achanna, S., Krishnaswamy, G., Ponnampalam, P., \& Bondhu, A. (2018). Maternal Mortality in Malaysia: Progress Made Towards Millennium Development Goal (MDG) 5 - An Analysis of Published Data. Knowledge Enterprises Incorporated Journals, 6(2), 1-14.

Acharya, D., Khanal, V., Singh, J. K., Adhikari, M., \& Gautam, S. (2015). Impact of mass media on the utilization of antenatal care services among women of rural community in Nepal. BMC Research Notes, 8(1), 1-6.

Ahadzadeh, A. S. \& Sharif, S. P. (2017). Online health information seeking among Malaysian women: Technology acceptance model perspective. SEARCH (Malaysia), 9(1), 47-70.

Akbarinejad, F., Soleymani, M. R., \& Shahrzadi, L. (2017). The relationship between media literacy and health literacy among pregnant women in health centers of Isfahan. Journal of Education and Health Promotion, 6(1), 1-17.

Archer, C. \& Kao, K. T. (2018). Mother, baby and Facebook makes three: Does social media provide social support for new mothers? Media International Australia, $168(1), 122-139$.

Asia Internet (2010). Retrieved on 29 December 2020. Retrieved from https://sites.google.com/site/internethistoryasia/book3.

Baker, B. \& Yang, I. (2018). Social media as social support in pregnancy and the postpartum. Sexual and Reproductive Healthcare, 17, 31-34.

Barnes, L. A. J., Barclay, L., McCaffery, K., \& Aslani, P. (2019). Complementary medicine products: Information sources, perceived benefits and maternal health literacy. Women and Birth, 32(6), 493-520.

Basir, S. M. A., Rahman, M. S. A., Abu Bakar, W. A. M., \& Shukri, N. A. M. (2018). 
(C) 2018, UCTS Publisher.

Submitted: 18 October 2020 Accepted: 19 December 2020 Published: 31 December 2020

Perception on postpartum dietary practices among malay women in Kuantan, Pahang. Journal of Allied Health Sciences, 2(1), 245-266.

Charness, N. \& Boot, W. R. (2015). Technology, gaming, and social networking. In Handbook of the Psychology of Aging: Eighth Edition. Elsevier Inc.

Dollarhide, M. E. (2019). Social Media Definition. Investopedia.

Domestication-Communication Theory (n.d.). Retrieved on 30 December 2020. Retrieved from https://www.communicationtheory.org/domestication/.

Fadzil, F., Shamsuddin, K., \& Puteh, S. E. W. (2016). Traditional postpartum practices among Malaysian mothers: A review. Journal of Alternative and Complementary Medicine, 22(7), 503-508.

Finlayson, K., Crossland, N., Bonet, M., \& Downe, S. (2020). What matters to women in the postnatal period: A meta-synthesis of qualitative studies. PLoS ONE, 15(4), $1-23$.

Ghani, R. A. \& Salehudin, S. (2018). Traditional belief and practice on postpartum recovery among mothers in East Coast of Peninsular Malaysia. In the proceeding of MATEC Web of Conferences, 150, 1-10.

Ginja, S., Coad, J., Bailey, E., Kendall, S., Goodenough, T., Nightingale, S., Smiddy, J., Day, C., Deave, T., \& Lingam, R. (2018). Associations between social support, mental wellbeing, self-efficacy and technology use in first-time antenatal women: Data from the BaBBLeS cohort study. BMC Pregnancy and Childbirth, 18(1), 111.

Goonawardene, N., Jiang, J., Tan, S. S., Park, S. I., \& Su, J. (2013). Online health information seeking and adolescents' intention towards health self-Management. In the proceeding of PACIS 2013, 1-16. Retrieved from http://www.pacisnet.org/file/2013/PACIS2013-174.pdf.

Guerra-Reyes, L., Christie, V. M., Prabhakar, A., Harris, A. L., \& Siek, K. A. (2016). Postpartum Health Information Seeking Using Mobile Phones: Experiences of Low-Income Mothers. Maternal and Child Health Journal, 20(1), 13-21.

Hakkak, H. M., Joveini, H., Rajabzadeh, R., Robatsarpooshi, D., Tori, N. A., Haresabadi, M., \& Hosseini, S. H. (2019). Health literacy level and related factors among pregnant women referring to bojnord health centers in 2017. International Journal of Pharmaceutical Research, 11(1), 152-158.

Hamzah, M. R., Mohamad, E. M. W., Abdullah, M. Y., \& Hadi Ayub, S. (2015). Scenario on health information seeking in Malaysia: A systematic review. Journal of Human Development and Communication, 4, 7-20.

Hla Myint, M., Rao, S., Mie., C. W. M., \& Rajan, P. (2019). Traditional practices during postpartum period among women in Ampang, Malaysia. Journal of Management and Science, 17(1), 98-105.

Huo, J., Desai, R., Hong, Y. R., Turner, K., Mainous, A. G., \& Bian, J. (2019). Use of social media in health communication: Findings from the health information national trends survey 2013, 2014, and 2017. Cancer Control, 26(1), 1-10.

Ikhsan, L. N., Nasaruddin, N. A. M., Othman, F., Aziz, K. H. A., \& Ismail, H. (2016). Nutritional knowledge, attitude and practice among antenatal and postnatal mothers in Hospital Tengku Ampuan Afzan (HTAA), Kuantan, Pahang 2016. International Medical Journal Malaysia, 17(1), 167-173.

Jamal, A., Khan, S. A., AlHumud, A., Al-Duhyyim, A., Alrashed, M., Shabr, F. Bin, 
(C) 2018, UCTS Publisher.

Submitted: 18 October 2020 Accepted: 19 December 2020 Published: 31 December 2020

Alteraif, A., Almuziri, A., Househ, M., \& Qureshi, R. (2015). Association of online health information - Seeking behavior and self-care activities among type 2 diabetic patients in Saudi Arabia. Journal of Medical Internet Research, 17(8), 1-15.

Jiao, N., Zhu, L., Chong, Y. S., Chan, W. C. S., Luo, N., Wang, W., Hu, R., Chan, Y. H., \& He, H. G. (2019). Web-based versus home-based postnatal psychoeducational interventions for first-time mothers: A randomised controlled trial. International Journal of Nursing Studies, 99, 1-11.

Khan, N., Qureshi, M. I., Mustapha, I., Irum, S., \& Arshad, R. N. (2020). A systematic literature review paper on online medical mobile applications in Malaysia. International Journal of Online and Biomedical Engineering, 16(1), 63-82.

Kim, S., Gray, H. L., Li, J., Park, H., Lee, Y., \& Song, K. (2019). A comparative study on nutritional knowledge and dietary behavior between Korean and Chinese postpartum women. Nutrition Research and Practice, 13(6), 535-542.

Kort-Butler, L. A. (2017). Social support theory. In The Encyclopedia of Juvenile Delinquency and Justice, 1-4, John Wiley \& Sons, Inc.

Lupton, D. (2016). The use and value of digital media for information about pregnancy and early motherhood: A focus group study. BMC Pregnancy and Childbirth, 16(1), 1-10.

Mbuthia, F., Reid, M., \& Fichardt, A. (2019). MHealth communication to strengthen postnatal care in rural areas: A systematic review. BMC Pregnancy and Childbirth, 19(1), 1-10.

Ministry of Health Malaysia. (2015). Traditional Postnatal Care in Restoring Women's Physical and Mental Health. 26.

Mohamad, E., Haniff, N. A. M., Salleh, S. M., Ahmad, A. L., \& Hashim, H. (2015). Media dan Literasi Kesihatan: Pemilihan Susu Tumbesaran Kanak-Kanak dalam Kalangan Ibu (Health and Media Literacy: The Choice of Milk Amongst Mothers for The Growth of Children). Jurnal Komunikasi, Malaysian Journal of Communication, 31(2), 83-97.

Mohanty, K., Nor, F. M., Sadek, N. F. M., Mar, O., \& Mohanty, B. (2020). Attitude towards traditional, complementary and alternative medicines (t\&cam) and its use among women during antenatal and postnatal period. Asian Journal of Medicine and Health Sciences, 3(1), 52-60.

Mun, W. C., Daud, F., Sivaratnam, L. A., \& Selimin, D. S. (2019). The "irrational" taboos and "irrelevant" traditions related to postpartum women's health and wellbeing. Sains Malaysiana, 48(5), 1055-1064.

Noman, M., Koo, A. C., Tee, S. H., \& Krishnan, M. (2019). Web elements for health promotion in Malaysia. Health Promotion International, 35(3), 458-469.

Noor, N. M., Hazlina, N. H. N., Aziz, A. A., \& Sulaiman, Z. (2016). Factors associated with severe maternal morbidity in Kelantan, Malaysia: A comparative crosssectional study. BMC Pregnancy and Childbirth, 16(1), 1-10.

Rahim, A. I. A., Ibrahim, M. I., Salim, F. N., \& Ariffin, M. A. I. (2019). Health information engagement factors in Malaysia: A content analysis of facebook use by the ministry of health in 2016 and 2017. International Journal of Environmental Research and Public Health, 16(4), 1-11.

Syed Hussien, S. F. A. (2019). The fading birth practice: Urban malay mothers in Malaysia negotiating confinement practice. IIUM Journal of Human Sciences, 1(2), 
(C) 2018, UCTS Publisher.

Submitted: 18 October 2020 Accepted: 19 December 2020 Published: 31 December 2020

$11-19$.

Shin, C. Y. \& Zanuddin, H. (2019). New media literacy and media use among university students in Malaysia. International Journal of Engineering and Advanced Technology, 8(5), 469-474.

Sørensen, K., Pelikan, J. M., Röthlin, F., Ganahl, K., Slonska, Z., Doyle, G., Fullam, J., Kondilis, B., Agrafiotis, D., Uiters, E., Falcon, M., Mensing, M., Tchamov, K., van den Broucke, S., Brand H; HLS-EU Consortium. (2015). Health literacy in Europe: comparative results of the European health literacy survey (HLS-EU). Eur J Public Health, 25(6), 1053-1058.

Monica Silva, B. (2017). The feasibility of providing nutrition education through a wic app to augment healthy eating, breastfeeding, and physical activity behaviors amoung wic participants. Master Thesis, Texas State University.

Tang, K., Gerling, K., Chen, W., \& Geurts, L. (2019). Information and communication systems to tackle barriers to breastfeeding: Systematic search and review. Journal of Medical Internet Research, 21(9), 1-15.

Vander Wyst, K. B., Vercelli, M. E., O’Brien, K. O., Cooper, E. M., Pressman, E. K., \& Whisner, C. M. (2019). A social media intervention to improve nutrition knowledge and behaviors of low income, pregnant adolescents and adult women. PLOS ONE, 14(10), 1-18.

Wilson, A. \& Williams, R. (2000). Sexual health services: What do teenagers want? Ambulatory Child Health, 6(4), 253-260.

Yusof, N. Y. M., Zulkefli, N. A. M., Ismail, S., \& Rashid, M. F. A. (2017). Inadequate health literacy on childhood immunization and its predictors among antenatal mothers. Malaysian Journal of Medicine and Health Sciences, 13(3), 51-59.

Yusuff, A. S. M., Tang, L., W.Binns, C., \& Lee, A. H. (2015). Prevalence and risk factors for postnatal depression in Sabah, Malaysia: A cohort study. Women and Birth, 28(1), 25-29.

Yusoff, Z. M., Amat, A., Naim, A., \& Othman, S. (2018). Postnatal care practices among the Malays, Chinese, and Indians: A comparison. In the proceeding of SHS Web of Conferences (45), 1-6. Universiti Sains Malaysia.

Zhu, C., Zeng, R., Zhang, W., Evans, R., \& He, R. (2019). Pregnancy-related information seeking and sharing in the social media era among expectant mothers in China: Qualitative study. Journal of Medical Internet Research, 21(12), 1-11.

Zimmerman, M. S. (2017). Reproductive health information needs and maternal literacy in the developing world: A review of the literature. IFLA Journal, 43(3), 227-241.

Zulkefli,N.A., Iahad, N. A., \& Yusof, A. F. (2018). Benefits of social media platform in healthcare. International Journal of Innovative Computing, 8(3), 59-63. 